Received: 2018.02.15 Accepted: 2018.04.04 Published: 2018.07.31

\title{
Pituitary Metastasis of Thyroid Carcinoma: A Case Report
}

Authors' Contribution: Study Design A Data Collection B Statistical Analysis C Data Interpretation D Manuscript Preparation E Literature Search F Funds Collection G

\author{
ABCDEF 1 Juliana Souza Mota \\ AF 1 Adriana de Sá Caldas \\ BC 2 Ana G.P. de Araújo Cortês Nascimento \\ ACF 1 Manuel dos Santos Faria \\ ACDEF 1 Carla Souza Pereira Sobral
}

1 Department of Endocrinology and Metabolism, University Hospital of the Federal University of Maranhão, Presidente Dutra Unit, São Luís, Maranhão, Brazil 2 Department of Pathology, University Hospital of the Federal University of Maranhão, Presidente Dutra Unit, São Luís, Maranhão, Brazil
Corresponding Author: Conflict of interest:
Juliana Souza Mota, e-mail: jsm.juli@gmail.com, jsm juli@yahoo.com.br None declared

\begin{abstract}
Patient: Male, 58
Final Diagnosis: Pituitary metastais from thyroid carcinoma

Symptoms: Visual acuity worsening

Medication: -

Clinical Procedure: Neurosurgery

Specialty: Endocrinology and Metabolic

Objective: Rare disease

Background: Pituitary metastasis of thyroid carcinoma is a rare entity. Differential diagnosis with other lesions in the sellar/ parasellar region, through clinical, histopathological, immunohistochemical, and imaging is challenging but essential for adequate treatment.

Case Report: This case report describes a 58-year-old patient with the previous diagnosis of follicular thyroid carcinoma, with metastasis to cervical lymph nodes, bone, and lung, initially evolving to left palpebral ptosis. In the investigation, laboratory tests showed hypopituitarism, and magnetic resonance imaging of the skull showed a suprasellar formation measuring $2.2 \times 3.5 \times 2.5 \mathrm{~cm}$, which increased in size in a few months. The patient underwent transcranial neurosurgery and subsequent immunohistochemical analysis, which confirmed pituitary metastasis of follicular thyroid carcinoma. The patient underwent chemotherapy and radiotherapy but died 26 months after the onset of symptoms.

Conclusions: The differential diagnosis of pituitary metastasis from a benign lesion is difficult. Therefore, a careful analysis of the history and clinical evolution, use of complementary imaging tests, and, where possible, the histopathological and immunohistochemical analysis of the lesion for diagnostic elucidation are necessary.
\end{abstract}

MeSH Keywords: $\quad$ Adenocarcinoma, Follicular • Diabetes Insipidus, Neurogenic • Immunohistochemistry • Pituitary Neoplasms • Thyroglobulin

Full-text PDF: https://www.amjcaserep.com/abstract/index/idArt/909523 


\section{Background}

Pituitary metastasis (PM) is a rare condition [1] in which patients may present symptoms related to hypopituitarism, mass effect, and diabetes insipidus [2]. Despite advances in imaging modalities, tumors that metastasize to the pituitary gland may be difficult to differentiate from an adenoma [3]. The prevalence of PM from thyroid carcinoma is around $2 \%$ [4], and the treatment options in these cases are radiotherapy, iodotherapy, chemotherapy, and/or surgery; although they do not increase survival, they allow better quality of life for the patient [3].

We report a rare case of PM from thyroid carcinoma in a 58-year-old male patient who initially developed palpebral ptosis, and the definitive diagnosis was only possible with immunohistochemistry.

\section{Case Report}

A 58-year-old male patient sought care at University Hospital of the Universidade Federal do Maranhão (HUUFMA) in São Luís, in the Brazilian state of Maranhão, in April 2016, complaining of a holocranial headache, retroorbital pain, and left visual acuity worsening, associated with ipsilateral eyelid ptosis, which began 8 months before.

When checking his medical history, the patient informed us about his previous diagnosis of thyroid carcinoma. The patient had undergone a subtotal thyroidectomy at another hospital in August of 2013, with an unknown histopathological result and without adequate medical follow-up. Eighteen months after the first surgery, a cervical ultrasound performed due to the appearance of cervical lymphadenopathy showed bilateral thyroid nodules. Cervical lymph node biopsy showed epithelioid lesion, and immunohistochemistry results were compatible with thyroid follicular carcinoma (FTC) metastasis with thyroglobulin, thyroid/lung transcription factor (TTF1), and positive proliferative cell index (Ki-67: 40\%).

The patient then underwent total thyroidectomy with neck lymph node dissection in October of 2015. The histopathological analysis of 46 lymph nodes showed metastatic spread to 34 of them with a solid epithelial neoplasia compatible with FTC. The immunohistochemistry analysis revealed expression for CD56+ and thyroglobulin, consistent with extensively invasive FTC.

In the follow-up, the patient underwent staging examinations. The computed tomography (CT) scan showed multiple nodular formations in the pulmonary parenchyma, the largest $(2.0 \mathrm{~cm})$ being in the left middle lobe. It also presented massive lymphadenopathy in para-aortic topography, measuring $4.5 \mathrm{~cm}$. An

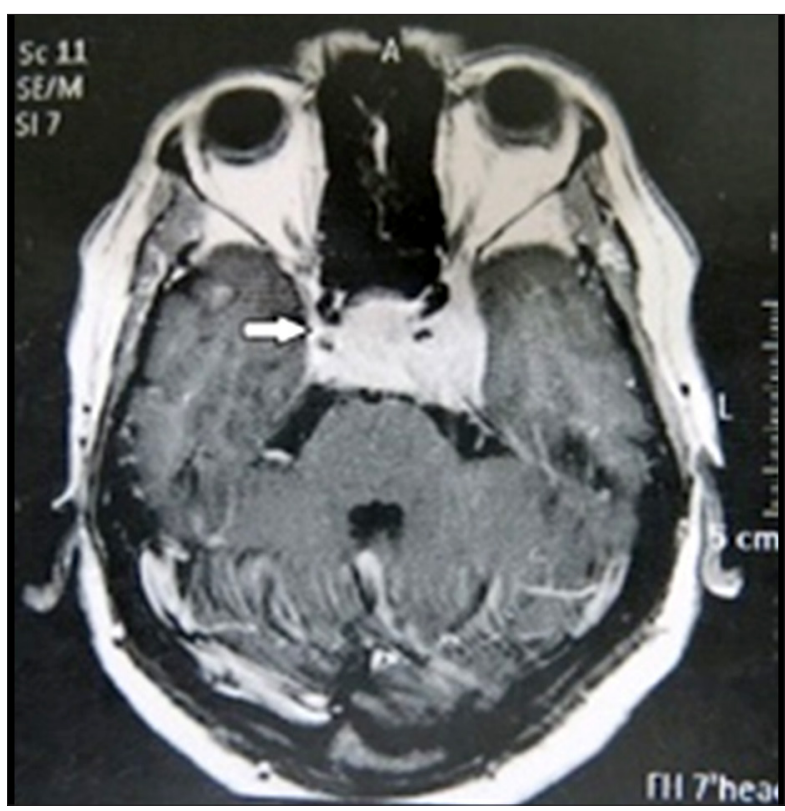

Figure 1. Magnetic resonance imaging of the skull, dated March 2016, a T1-weighted image with a lesion of $2.2 \times 3.5 \times 2.5 \mathrm{~cm}$, with intense contrast enhancement (white arrow).

expansive process affecting soft parts and the sternum bone measuring $5.7 \times 4.9 \mathrm{~cm}$ with pathological fracture was also observed. Magnetic resonance imaging (MRI) of the skull, dating from March 2016, showed an enlarged suprasellar formation measuring $2.2 \times 3.5 \times 2.5 \mathrm{~cm}$ (Figure 1), with a weighted image in $\mathrm{T} 1$ and $\mathrm{T} 2$ and intense contrast enhancement, compromising the left cavernous sinus, suggesting pituitary adenoma. At the time, serum thyroglobulin was $30000 \mathrm{ng} / \mathrm{dL}$ and calcitonin was less than $2 \mathrm{ng} / \mathrm{dL}$. The patient then received an iodine dose of $250 \mathrm{mCi}$, and the post-dose full-body investigation only showed uptake in the anterior cervical region, without distant capture.

Due to left amaurosis and worsening of right-side vision, the patient sought care at HUUFMA and was admitted in August of 2016. He complained of dizziness, nausea, and episodes of diarrhea. In the physical examination, multiple lymph nodes in the right and left cervical region were observed, in addition to the left supraclavicular lymph node and mass in the bone region of the sternum, which was hardened, fixed, and painless. Laboratory tests showed suppressed thyroid-stimulating hormone (TSH), mildly elevated prolactin, hypogonadotropic hypogonadism, hypocortisolism, and hypoparathyroidism (Table 1).

The MRI of the sella turcica revealed a suprasellar image measuring $4.1 \times 5.1 \times 5.0 \mathrm{~cm}$ (Figure 2A, 2B). New staging showed lesions in the pulmonary parenchyma and sternum, multiple cervical nodules, and a secondary implant in the acetabular region. The patient then underwent transcranial neurosurgery 
Table 1. Laboratory tests of the patient and their respective reference values.

\begin{tabular}{|c|c|c|}
\hline & Results & Reference \\
\hline Testosterone & $<0.025 \mathrm{ng} / \mathrm{mL}$ & $(1.93-7.40)$ \\
\hline $\begin{array}{l}\text { Follicle-stimulating hormone } \\
\text { (FSH) }\end{array}$ & $1.37 \mathrm{mUl} / \mathrm{mL}$ & $(1.5-12.4)$ \\
\hline Luteinizing hormone (LH) & $1.18 \mathrm{mUl} / \mathrm{mL}$ & $(1.7-8.6)$ \\
\hline Prolactin & $18.79 \mathrm{ng} / \mathrm{mL}$ & $(4.04-15.2)$ \\
\hline Free T4 (Thyroxine) & $19.24 \mathrm{pmol} / \mathrm{L}$ & $(12-22)$ \\
\hline $\begin{array}{l}\text { Thyroid-stimulating hormone } \\
\text { (TSH) }\end{array}$ & $0.02 \mathrm{mU} / \mathrm{L}$ & $(0.51-4.9)$ \\
\hline Cortisol 8: 00 & $3.3 \mu \mathrm{g} / \mathrm{dL}$ & $(6.7-22.6)$ \\
\hline $\begin{array}{l}\text { Adrenocorticotropic hormone } \\
\text { (ACTH) }\end{array}$ & $12.2 \mathrm{pg} / \mathrm{mL}$ & Up to 46 \\
\hline Parathyroid hormone (PTH) & $1 \mathrm{pg} / \mathrm{mL}$ & $(4-58)$ \\
\hline
\end{tabular}

and developed diabetes insipidus postoperatively. The histopathological of the pituitary mass demonstrated solid epithelial pattern neoplasia with similar characteristics to the lymph nodes and thyroid, composed of cells with regular nuclei and eosinophilic/oncocytic cytoplasm. The immunohistochemistry study showed thyroglobulin expression, paired box gene 8 (PAX8), and TTF1, and was negative for pituitary hormones. Those findings were consistent with PM from thyroid carcinoma.

The oncology team joined the treatment and the tyrosine kinase inhibitor sorafenib $800 \mathrm{mg} /$ day was used by the patient for 5 months but was discontinued due to hepatotoxicity and clinical worsening.

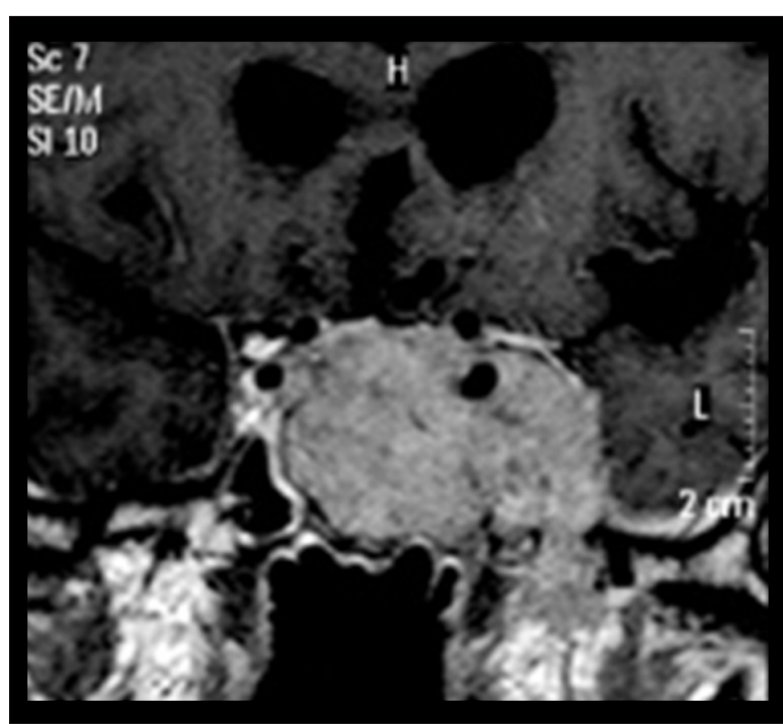

Figure 3. MRI 5 months after surgery, showing that there was no significant reduction of the lesion. Image weights in T1, with lesion measuring $4.6 \times 5.1 \times 5.1 \mathrm{~cm}$ with enhancement after contrast.

The MRI of the sella turcica performed 5 months after the surgery showed a still voluminous intra- and supra-sellar expansive lesion measuring $4.6 \times 5.1 \times 5.1 \mathrm{~cm}$ (Figure 3 ). The chest CT revealed a volumetric increase of the retrosternal mediastinal lesion and a reduction in the number of pulmonary lesions, with stabilization of the more extensive lesions.

In follow-up with oncology, radiotherapy was provided for bone and cervical lesions, but these continued evolving with little improvement. After 12 months of surgery, radiotherapy was provided for PM. However, after beginning the sessions, the patient died.

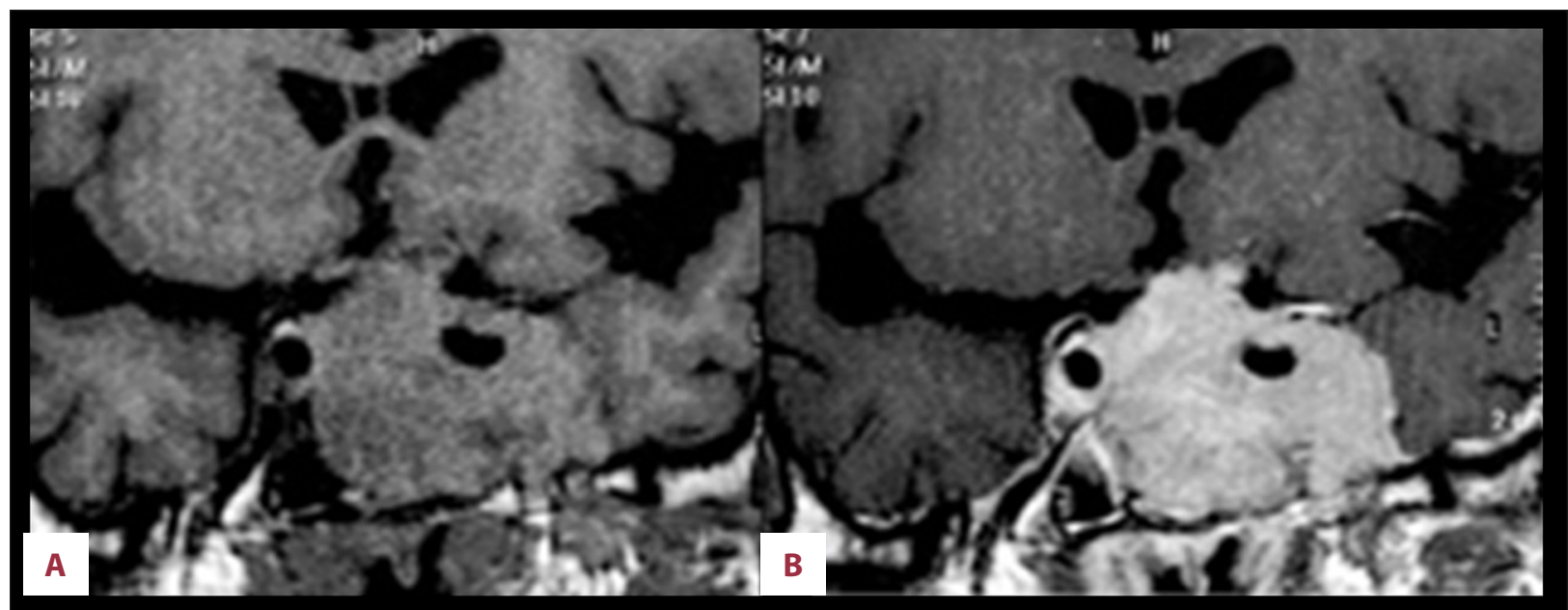

Figure 2. (A) Magnetic resonance imaging of sella turcica performed in August 2016, weighted in T1, coronal, with isointense lesion of $4.1 \times 5.1 \times 5.0 \mathrm{~cm}$. (B) Intense enhancement of the lesion after contrast (gadolinium). 


\section{Discussion}

Metastatic tumors of the pituitary and sellar region occur in $1 \%$ to $3.6 \%$ of cancer patients $[5,6]$. The most common malignancy with PM is lung cancer in men and breast cancer in women [4,7-9]. Usually, they affect patients in the sixth or seventh decade of life, with no clear sex predominance $[3,8]$. Other pituitary metastases have already been reported, such as prostate tumors, renal, gastrointestinal, thyroid, and other primary sites $[3,10]$. Thyroid carcinoma metastasis to the pituitary gland is rare [11], and accounts for only $2 \%$ of PM $[1,4,12]$.

Thyroid carcinoma is divided into 4 main subtypes: papillary, follicular, medullary, and anaplastic [12]. The most common is papillary thyroid carcinoma (PTC), followed by follicular thyroid carcinoma (FTC) [13]. In the latter, the main route of dissemination is hematogenous, resulting in metastases to distant areas, mainly bones and lungs, and rarely pituitary. In the case described, the patient was a man in the sixth decade of life with a diagnosis of PM from FTC.

Metastatic tumors may involve the pituitary by hematogenous dissemination, direct invasion of metastasis from the skull base, or meningeal spread through the suprasellar cisterna $[8,10]$. As the neurohypophysis is directly exposed to the arterial circulation, PM has a predilection for it $[7,8,11]$. Metastatic inoculation of the adenohypophysis is usually a result of the contiguous dissemination from the posterior lobe $[3,8]$.

Pituitary metastases from thyroid carcinoma tend to be fastgrowing parasellar lesions that destroy the pituitary tissue or compress the pituitary stem [1]. In our case, it was difficult to determine the mode of propagation given the rapid and aggressive growth of the carcinoma; also, there was no report of impairment of skull base bones in the imaging studies.

Clinically, suspicion of metastases is warranted in patients with rapid onset and progressive symptoms, regardless of history of malignancy [3,7]. Presentation often includes polyuria, polydipsia, headache, hypopituitarism, visual field defects, and cranial nerves lesions [14]. The vast majority of patients with PM have diabetes insipidus $[6,8,9,15,16]$. However, if the anterior pituitary function is impaired, diabetes insipidus may be hidden due to the reduction of glucocorticoid function, becoming evident after starting corticosteroid treatment $[3,8]$.

A decrease in the presence of diabetes insipidus in cases of PM from thyroid carcinoma has been reported in the literature, although the reasons for such an uncommon presentation have not been clearly established. A possible hypothesis is that PM from thyroid carcinoma tends to initially exhibit a higher parassellar growth in relation to the intrassellar growth [1] Parasellar growth causes impairment mainly of cranial nerves present in the cavernous sinuses; clinical manifestations of diplopia, ptosis, or unilateral ophthalmoplegia rapidly progressive with retroorbital pain resulting from such impairment are the initial presentation of these cases [3].

Intrasellar growth, in turn, destroys the pituitary tissue, with compression of the pituitary stem and consequent hormonal production loss [1]. Hypopituitarism in cases of metastasis may also result more frequently from hypothalamic invasion than adeno-pituitary invasion [17]. Clinically, the symptoms of adenohypophysis dysfunction are usually hidden by the signs of systemic disease due to malignancy $[5,6]$. Hyperprolactinemia was found in $6.3 \%$ of pituitary metastases and is generally attributed to the compression of the stem $[8,16]$.

Table 2 summarizes some clinical findings of the 14 cases (including ours) of PM from FTC found in the literature. Diabetes insipidus was present in only 1 of the 14 cases, showing the different behavior of the FTC metastasis. In 8 of the 14 cases, the cranial nerves were affected, and hypopituitarism was reported in the initial investigation in only 3 cases. In the case reported here, the patient presented symptoms related to mass effect, hypopituitarism, and left ptosis, characterizing the involvement of the oculomotor nerve. Diabetes insipidus was a post-surgical complication.

Despite advances in imaging methods, tumors that metastasize to the sellar/parasellar region may still be difficult to differentiate from pituitary adenoma [3,8]. Metastatic tumors can mimic a variety of lesions in the sellar region, confusing diagnosis [8].

Computed tomography and MRI are sensitive but non-specific imaging modalities [2]. Computed tomography usually shows hyperdense or isodense, homogeneous, or non-presence of cystic degeneration, hemorrhage, or necrosis [8]. In an MRI, it shows as an isointense or hypointense mass in $\mathrm{T} 1$ with a hyperintense signal in $\mathrm{T} 2$ and homogeneous enhancement after contrast $[2,3,8,12]$. However, Mayr et al. [7] showed the majority of PMs are isointense in T1 and T2 images.

Changes such as metastatic lesions in another area of the central nervous system, invasion of the cavernous sinus, sclerotic changes around the sella turcica and clivus, isointense signal in both T1 and T2 images, and loss of the hypersignal of the neurohypophysis have been useful in the differentiation of benign, metastatic lesions [4-6]. An intra- and suprasellar tumor dumbbell-shaped indentation at the diaphragm level may also be indicative of PM $[3,6,8,12]$.

Histopathological analysis of PM may indicate pituitary adeno$\mathrm{ma}$, and immunohistochemistry is required for diagnostic confirmation [18]. Thyroid follicular carcinomas exhibit a variable 
Table 2. Characteristics of pituitary metastases of follicular thyroid carcinoma described in the literature.

\begin{tabular}{|c|c|c|c|c|c|c|}
\hline Cases & Age, sex & $\begin{array}{c}\text { Pituitary hyposecretion } \\
\text { syndrome }\end{array}$ & $\begin{array}{c}\text { DI } \\
\text { Initial }\end{array}$ & $\begin{array}{c}\text { NCs } \\
\text { III, IV, VI }\end{array}$ & $\begin{array}{c}\text { Other } \\
\text { metastases }\end{array}$ & Treatment \\
\hline $\begin{array}{l}\text { Lim et al. (2015) } \\
\text { [1] }\end{array}$ & $65, \mathrm{~F}$ & Yes & Yes & No & Lung bone & $\begin{array}{l}\text { Neurosurgery } \\
\text { lodotherapy }\end{array}$ \\
\hline $\begin{array}{l}\text { Matyja et al. (2013) } \\
\text { [17] }\end{array}$ & $53, \mathrm{~F}$ & No & No & Yes (VI) & Cervical bone & $\begin{array}{l}\text { Neurosurgery } \\
\text { Radiotherapy }\end{array}$ \\
\hline $\begin{array}{l}\text { Aleyadeh et al. (2012) } \\
\text { [21] }\end{array}$ & $49, F$ & No & NR & No & Cervical bone & $\begin{array}{l}\text { Neurosurgery } \\
\text { lodotherapy }\end{array}$ \\
\hline $\begin{array}{l}\text { Vianello et al. (2011) } \\
\text { [22] }\end{array}$ & $61, \mathrm{~F}$ & Yes & No & No & Lung bone & $\begin{array}{l}\text { Biopsy TE } \\
\text { Radiotherapy } \\
\text { lodotherapy }\end{array}$ \\
\hline $\begin{array}{l}\text { Chhiber et al. (2011) } \\
\text { [23] }\end{array}$ & $65, F$ & No & No & Yes (III) & Bone & $\begin{array}{l}\text { Neurosurgery } \\
\text { lodotherapy }\end{array}$ \\
\hline $\begin{array}{l}\text { Prodam et al. (2010) } \\
\text { [9] }\end{array}$ & $45, F$ & No & No & Yes (III) & Cervical bone & $\begin{array}{l}\text { Neurosurgery } \\
\text { lodotherapy }\end{array}$ \\
\hline $\begin{array}{l}\text { Yilmazlar et al. (2004) } \\
\text { [24] }\end{array}$ & $43, F$ & No & No & No & Lung bone & $\begin{array}{l}\text { Neurosurgery } \\
\text { lodotherapy }\end{array}$ \\
\hline $\begin{array}{l}\text { Chrisoulidou et al. } \\
\text { (2004) [15] }\end{array}$ & $60, M$ & No & NR & Yes (III) & No & $\begin{array}{l}\text { Neurosurgery } \\
\text { Radiotherapy } \\
\text { lodotherapy }\end{array}$ \\
\hline $\begin{array}{l}\text { Simon 2004, (apud } \\
\text { Lim } 2015 \text { [1]) }\end{array}$ & $23, F$ & No & No & Yes (IV) & No & $\begin{array}{l}\text { Neurosurgery } \\
\text { lodotherapy }\end{array}$ \\
\hline $\begin{array}{l}\text { Kucuk } 2002 \text { et al. } \\
{[25]}\end{array}$ & $44, F$ & NR & NR & NR & $\mathrm{Nr}$ & NR \\
\hline $\begin{array}{l}\text { Ochiai et al. (1992) } \\
\text { [26] }\end{array}$ & $62, \mathrm{~F}$ & No & No & Yes III,VI & No & $\begin{array}{l}\text { Neurosurgery } \\
\text { lodotherapy }\end{array}$ \\
\hline $\begin{array}{l}\text { Kistler et al. (1975) } \\
\text { [27] }\end{array}$ & $50, M$ & NR & No & $\begin{array}{l}\text { Yes } \\
\text { (III) }\end{array}$ & Bone & $\begin{array}{l}\text { Neurosurgery } \\
\text { lodotherapy } \\
\text { Radiotherapy }\end{array}$ \\
\hline $\begin{array}{l}\text { Trunnell et al. (1949) } \\
\text { [28] }\end{array}$ & $42, \mathrm{~F}$ & NR & No & No & $\mathrm{Nr}$ & lodotherapy \\
\hline Our case (2017) & $58, M$ & Yes & No & Yes (III) & Bone cervical lung & $\begin{array}{l}\text { Neurosurgery } \\
\text { lodotherapy } \\
\text { Chemotherapy } \\
\text { Radiotherapy }\end{array}$ \\
\hline
\end{tabular}

DI - diabetes insipidus; CNs - cranial nerves; NR - not reported; F - Female; $M$ - Male; TE - transsphenoidal.

morphology, from the presence of small or medium follicles containing colloid to a trabecular or solid growth pattern [19]. The latter tends to be more frequent in invasive FTCs but may also occur in extremely invasive FTCs [19]. The histopathological of the neurosurgery product was compatible with solid epithelial neoplasia with characteristics like the neoplasia seen in the cervical and thyroid lymph nodes.

In immunohistochemistry tests, TTF1 and thyroglobulin are useful for distinguishing between thyroid carcinoma and pulmonary adenocarcinoma $[14,20]$. Thyroid transcription factor
1 is a marker of immunohistochemistry used to confirm lung and thyroid carcinoma, while thyroglobulin is a thyroid carcinoma marker $[14,20]$. The immunohistochemistry of our patient's pituitary lesion was positive for TTF1, thyroglobulin, and PAX8, confirming PM from FTC.

Treatment of metastases of thyroid carcinoma includes surgery, radiotherapy, iodoteraphy, and chemotherapy [3]. Neurosurgical exploration may lead to significant symptomatic relief, confirmation of diagnosis, and improvement in quality of life, but without an increase in life expectancy [14]. Total resection is 
complicated due to increased tumor vasculature and local invasiveness [16]. Surgical treatment should be followed by local radiotherapy and/or chemotherapy [3]. The morbidity of surgery and radiotherapy includes hypopituitarism, diabetes insipidus, and visual disturbances, and consciousness disorders [4].

Table 2 shows that the primary treatment in the cases already reported was neurosurgery. Our patient underwent neurosurgery because of the compressive effect of the lesion on the optic chiasm, and, later, chemotherapy and radiotherapy for cervical, bony, and pituitary metastases were indicated.

Chemotherapy for metastatic thyroid carcinoma has a limited role due to low response and significant adverse effects [2]. Radioiodine therapy is also an alternative; however, in patients with poorly differentiated thyroid carcinoma, there is the reduced uptake of ${ }^{131}$ iodine, which reduces its effectiveness [1].

Despite aggressive therapy, even in patients without other metastasis in the initial assessment, the prognosis is poor for patients with thyroid carcinoma metastasis to the pituitary gland $[3,4,8]$. Patients with a single metastasis of the sellar/parasellar region tend to have a better outcome [3]. In contrast, advanced age at diagnosis decreases survival [13].

Control of the primary tumor directly affects survival [4]. Altay et al. [3] reported the average survival is less than 2 years, regardless of the management strategy. The cause of death may be progression of the primary tumor, extracranial

\section{References:}

1. Lim W, Lim DS, Chng CL, Lim AY: Case report thyroid carcinoma with pituitary metastases: 2 case reports and literature review. Case Rep Endocrinol, 2015; 2015: 252157

2. Chikani V, Lambie D, Russell A: Pituitary metastases from papillary carcinoma of thyroid: A case report and literature review. Endocrinol Diabetes Metab Case Rep, 2013; 2013: 130024

3. Altay T, Krisht KM, Couldwell WT: Sellar and parasellar metastatic tumors. Int J Surg Oncol, 2012; 2012: 647256

4. Habu M, Tokimura $\mathrm{H}$, Hirano $\mathrm{H}$ et al: Pituitary metastases: Current practice in Japan. J Neurosurg, 2015;123: 998-1007

5. Fassett DR, Couldwell WT: Metastases to the pituitary gland. Neurosurg Focus, 2004; 16: E8

6. Cieszynski L, Obolonczyk L, Sworczak K et al: Diabetes insipidus as a main symptom of cancer. Arch Med Sci, 2014; 10: 401-5

7. Mayr NA, Yuh WT, Muhonen MG et al: Pituitary metastases: MR findings. J Comput Assist Tomogr, 1993; 17: 432-37

8. Komninos J, Vlassopoulou V, Protopapa D et al: Clinical case seminar tumors metastatic to the pituitary gland: case report and literature review. J Clin Endocrinol Metab, 2004; 89: 574-80

9. Prodam F, Pagano L, Belcastro $S$ et al: Pituitary metastases from follicular thyroid carcinoma. Thyroid, 2010; 20: 823-30

10. Samaras I, Tsapakidis K, Maragouli E et al: Metastatic breast carcinoma to the pituitary gland that presented as diabetes insipidus: A case report. J Cancer Prev Curr Res, 2017; 8: 00273

11. Masiukiewicz US, Nakchbandi IA, Stewart AF, Inzucchi SE: Papillary thyroid carcinoma metastatic to the pituitary gland. Thyroid, 1999; 9: 1023-27 metastatic lesion, extra-pituitary intracranial metastatic lesions, and worsening of the pituitary lesion [4]. Our patient had a 26-month survival time after the onset of symptoms.

Thus, early diagnosis and involvement of a multi-professional team are fundamental for the treatment of such patients.

\section{Conclusions}

This case report contributes to the scientific literature on the rare occurrence of PM-FTC, showing clinical manifestations that differ in part from those reported previously regarding the presence of hypopituitarism and absence of diabetes insipidus in the initial evaluation. We show the importance of imaging characteristics, histopathological study, and immunohistochemistry with TTF1 and thyroglobulin markers for accurate diagnosis. A complete evaluation is critical for differential diagnosis with other potentially treatable benign sellar masses.

\section{Acknowledgments}

We thank the Endocrinology and Metabolism Department staff of the medical residency service of the Hospital Universitário da Universidade Federal do Maranhão, Unidade Presidente Dutra.

\section{Conflict of interests}

None.

12. Barbaro D, Desogus N, Boni G: Pituitary metastasis of thyroid cancer Endocrine, 2013; 43: 485-93

13. Shen J, Wang $S$, Zhao $X$ et al: Skull metastasis from follicular thyroid carcinoma: Report of 3 cases and review of literature. Int J Clin Exp Pathol, 2015; 8: 15285-93

14. Stojanović M, Pekić S, Doknić $M$ et al: What's in the image? Pituitary metastasis from papillary carcinoma of the thyroid: A case report and a comprehensive review of the literature. Eur Thyroid J, 2013; 1: 277-84

15. Chrisoulidou A, Pazaitou-Panayiotou K, Flaris N et al: Pituitary metastasis of follicular thyroid carcinoma. Horm Res, 2004; 61: 190-92

16. Wendel C, Campitiello M, Plastino F et al: Pituitary metastasis from renal cell carcinoma: description of a case report. Am J Case Rep, 2017; 18: 7-11

17. Pacheco FA, Oliveira LCL, Franco CAB, Vaisman M: [Pan-hypopituitarism by hypothalamic-pituitary metastases of squamous carcinoma of the lung]. J. Pneumol, 1997; 23: 267-70 [in Portuguese]

18. Matyja E, Zieliński G, Witek P et al: Pituitary metastases from the oncocytic variant of follicular thyroid carcinoma: A case report and diagnostic dilemas. Folia Neuropathol, 2013; 51: 261-68

19. Sobrinho-Simões M, Eloy C, Magalhães J et al: Follicular thyroid carcinoma. Modern Pathology, 2011; 24: S10-18

20. Matsuno A, Murakami M, Hoya K et al: Clinicopathological and molecular histochemical review of skull base metastasis from differentiated thyroid carcinoma. Acta Histochem Cytochem, 2013; 46: 129-36

21. Aleyadeh AA, Haddad FH, AL-omari AA, Al Sarihin KK: Pituitary metastasis of follicular thyroid carcinoma: A case report and review of the literature. Rawal Medical Journal, 2012; 37: 61-65 
22. Vianello F, Mazzarotto R, Taccaliti A et al: Follicular thyroid carcinoma with metastases to the pituitary causing pituitary insufficiency. Thyroid, 2011; 21: $921-25$

23. Chhiber SS, Bhat AR, Khan SH et al: Apoplexy in sellar metastasis: A case report and review of literature. Turk Neurosurg, 2011; 21: 230-34

24. Yilmazlar S, Kocaeli H, Corda T: Sella turcica metastasis from follicular carcinoma of thyroid. Neurol Res, 2004; 26: 74-78

25. Kucuk NO, Arican P, Aras G, Kir KM: A hypophyseal metastasis of follicular thyroid carcinoma. Clin Nucl Med, 2002; 27: 309-10
26. Ochiai $\mathrm{H}$, Nakano S, Goya T et al: Pituitary metastasis of thyroid follicula adenocarcinoma. Case report. Neurol Med Cir (Tokyo), 1992; 32: 851-53

27. Kistler M, Pribram HW: Metastatic disease of the sella turcica. Am J Roentgenol Radium Ther Nucl Med, 1975; 123: 13-21

28. Trunnel JB, Marinelli LD: The treatment of metastatic thyroid cancer with radioactive iodine; credits and debits. J Clin Endocrinol Metab, 1949; 9 1138-52 